\title{
Microbial ecogenomics and forensic archaeology: new methods for investigating clandestine gravesites
}

\author{
T. K. Ralebitso-Senior Teesside University \\ k.ralebitso-senior@tees.ac.uk
}

\section{T. J. U. Thompson Teesside University \\ t.thompson@tees.ac.uk}

H. E. Carney Teesside University

h.carney@tees.ac.uk

\begin{abstract}
In the mid-1990s, the crime scene toolkit was revolutionised by the introduction of DNA-based analyses such as the polymerase chain reaction, low copy number DNA analysis, short-tandem repeat typing, pulse-field gel electrophoresis and variable number tandem repeat. Since then, methodological advances in other disciplines, especially molecular microbial ecology, can now be adapted for cutting-edge applications in forensic contexts. Despite several studies and discussions, there is, however, currently very little evidence of these techniques' adoption at the contemporary crime scene. Consequently, this article discusses some of the popular 'omics' and their current and potential exploitations in the 'forensic ecogenomics' of body decomposition in a crime scene. Thus, together with published supportive findings and discourse, knowledge gaps are identified. These then justify the need for more comprehensive, directed, concerted and global research towards state-ofthe-art microecophysiology method application and/or adaptation for subsequent successful exploitations in this additional context of microbial forensics.
\end{abstract}

Key words: forensic science, crime scene, molecular microbial ecology, ecogenomics

\section{Introduction}

The detection of clandestine gravesites and areas of surface body deposition is of vital importance in a range of forensic contexts, but particularly in the investigation of acts of mass violence. Generally this can be achieved through the use of eye witness statements, aerial photography and field walking. However, there are occasions when graves are reopened and the remains moved elsewhere or, indeed, dug and never used. Determining whether or not a grave has been used in these situations can be difficult. Traditional archaeological methods that focus directly on the grave $e^{1}$ and the presence of small human remains or associated personal effects 
may be helpful. ${ }^{2}$ These approaches are, however, dependent on meticulous site excavation, which may not always be achievable. An alternative may be to examine the surrounding soil. Work has shown that decomposition alters indigenous soil microbial community profiles ${ }^{3}$ and there is, therefore, potential to use these detectable changes to determine grave locations and use. Although a very technical approach to the investigation of events of mass violence has been cautioned, advanced scientific techniques do have a role to play if deployed sensitively. ${ }^{4}$

The forensic sciences have an ability to co-opt methods and procedures from other disciplines to enhance expertise at a crime scene with forensic evidence. It is well recognised that molecular analyses have revolutionised this discipline as a whole, from collecting evidence and intelligence on site to informing court decisions. Particularly well-publicised applications focussed on body tissues and fluids and human identification and verification. ${ }^{5}$ Although only currently offering potential, there is now a developing appreciation that the directed scrutiny of microbial communities can contribute to the study and identification of people and bodies. ${ }^{6}$ Within the forensic sciences, there is great debate surrounding the boundaries of the term 'microbial forensics'. ${ }^{7}$ However, since our interest focusses on the gravesite and not the individual per se, we propose a more encompassing 'forensic ecogenomics' for the application of molecular microbial ecology techniques at the interface of (environmental) forensics, microbiology and archaeology, and thus expand on initial applications of microbiological analyses of soil. ${ }^{8}$

This perspective thus seeks to highlight 'forensic ecogenomics' as another aspect of the 'microbial forensics' category with current applications and the potential exploitation of popular and novel microbial ecology techniques in contemporary crime scene investigations. The ultimate proposal is to make stronger links between soil and aquatic microbial profiles and clandestine burial sites, in particular. Suggestions for additional methodological adoption are also made to ensure that microbial forensics, as an exciting new field of study and investigative discipline, is fit-for-purpose and applicable to wider but relevant contexts.

Specific attention is therefore given to decomposition-related microbioforensic studies published between 2000 and 2014. The application of ecogenomic protocols has then focussed on those with the highest potential for immediate extended applications in real-life scenarios (Table 1). The microecophysiology tools considered include denaturing gradient gel electrophoresis (DGGE), fatty acid methyl ester analysis (FAME), length heterogeneity PCR (LH-PCR), phospholipid fatty acid analysis (PLFA), polymerase chain reaction (PCR), terminal restriction fragment length polymorphisms (t-RFLP), next generation sequencing and microarrays/genechips as used, or for potential application, in measuring ecosystem response to burial and subsequent decomposition.

\section{Burial and decomposition in soil}

Soil is recognised in microbial ecology as a complex and heterogeneous environment that supports a vast number of phylogenetically, phenotypically and functionally diverse microbial populations. While the scientific discipline is changing, 
until recently soil was often considered in forensic science as essentially a burial medium where human and animal remains decompose. Typically, decomposition processes are mediated by changing indigenous microbial communities, especially bacteria, which are most abundant. ${ }^{9}$ According to Carter et al., the burial and subsequent decomposition of cadavers in a grave was often determined to be ecologically localised, releasing organic resources that were spatially and temporally finite. As a result, studies of soil in the burial context tended to focus on the localised influence of temperature or $\mathrm{pH}$ on the rate of decomposition. ${ }^{10}$ Nevertheless, several researchers reported that chemical, biological and physical changes occur in the burial site in response to the corpse and its resultant decay. ${ }^{11}$ These processes are mutual and each impacts on the other. Typically, high temperatures increase the rate of decomposition and, in turn, soil temperatures increase with advanced decay. ${ }^{12}$ Fluctuations in $\mathrm{pH}$, sometimes in relation to oxic or anoxic conditions, have been recorded where the production of ammonia and volatile fatty acids led to increases and decreases in soil $\mathrm{pH}$, respectively.

Expectedly, these interacting processes will both lead to changes in, and be partly dependent on, the local microbial communities. Complex scenarios arise, therefore, due to the number of soil types, the way in which the unique and individual properties influence and/or are affected by the added remains, the indigenous microbial communities, local climatic conditions and nutrient availability. As a result, the decompositional effects of these variables and different environmental parameters, such as moisture content, $\mathrm{pH}$, temperature and anion and cation concentrations have been explored in different soils. Thus, Hopkins et al. assessed variables in 430-day grave soils of four- to five-month old pigs, which were between 5 and $20 \mathrm{~m}$ from the grave of a murder victim. The researchers recorded increases in several parameters including microbial biomass $\mathrm{C}$, microbial respiration, nitrogen mineralisation and $\mathrm{pH}$ in comparison to the controls $(1 \mathrm{~m}$ away from each grave). ${ }^{13}$ Haslam and Tibbett made a laboratory-based study of the effects of lamb (Ovis aries) skeletal muscle tissue decomposition in three soils with different $\mathrm{pH}$ values - a Podzol ( $\mathrm{pH} 4.6$ ), Cambisol Brown Earth ( $\mathrm{pH}$ 6.4) and Rendzina ( $\mathrm{pH}$ 7.8 ) - and found that decomposition and substrate-induced respiration increased in the acidic Podzol in combination with a slightly higher $\mathrm{CO}_{2}$ evolution while the alkaline Rendzina recorded the highest microbial biomass. ${ }^{14}$ The effect of moisture on decomposition in Brown Sodosol (loamy sand), Rudosol (sandy) and Grey Vertosol (medium clay) was tested by Carter et al. where higher decomposition rates resulted from increased wetness for the two sandy soils. ${ }^{15}$

Overall, the original soil characteristics and the early-phase decomposition byproducts select for specific microbial communities and the size of the impacted area. These affect the rate of mid- to late-phase decomposition, subsequent byproducts and, in turn, microbial respiration rates and biomass (population size) that show soil-specific responses. For example, Parkinson et al. applied PLFA and t-RFLP analyses of bacterial and fungal profiles to human burial soils and reported distinct changes in fungal populations between the early and late phases of cadaver decomposition. These clear delineations were attributed to changes in the amounts and types of substrates that were available as a direct result of decomposition. An 
increase in nutrients will thus be accompanied by an abundance of the r-strategists while a decrease in labile substrates will result in higher numbers of the typically slow-growing k-strategists. The authors also suggested that sequential changes in community profiles could be linked, potentially, to post-mortem interval (PMI) estimation as with insect colonisation in forensic entomology. ${ }^{16}$

Length heterogeneity PCR was applied by Moreno et al. to study the response of soil microbial communities to cadaver decomposition, particularly in shallow clandestine graves during a sixteen-week period across nine different sites. Together with changes in community compositions of specific functional microbial clades/ genes such as nitrogen fixers and the nifH gene, the occurrences of different intestinal, oral and skin commensal microbiota were recorded. These were attributed to unique microbiome fingerprints specific to each of the bodies. As a result, the authors proposed that LH-PCR could be another reliable body identification technique in criminal or missing person cases. ${ }^{17}$

Apart from bacteria, other microorganisms such as fungi, and their recognised diversity, can be exploited in a field termed 'forensic mycology'. ${ }^{18}$ A comprehensive review by Hawksworth and Wiltshire considered the use of fungi as potential targets for diverse applications including the estimation of time since death, burial location, time of deposition, biological warfare investigations and the enforcement of legislation such as the Drugs Act 2005. ${ }^{19}$ Some researchers also recorded the consistent occurrence of fruiting structures in specific fungi, such as Penicillium sp., Aspergillus terreus and Eurotium spp. in response to mammalian/human decomposition. ${ }^{20}$ The studies were made in situ in clandestine graves and/or with real site materials from different environments including forests and a domestic garden. In particular, Ishii et al. reported the first study where taxonomic determinations of the appearance of fungal strains on a decomposing cadaver were made to suggest the PMI. ${ }^{21}$ Other strains, such as Trichophyton mentagrophytes, were then used in vitro on the hair of adult corpses to investigate the perforation test in the gaseous post-mortem period to establish time since death. ${ }^{22}$

Despite these demonstrable achievements, there are several issues to resolve including the dwindling number of specialist mycologists. Also, the numbers (and types) of fungi in a single location are vast with comprehensive inventories impractical and unattainable (particular spores and fruiting bodies of some species are produced infrequently), and appropriate and extensive experimentation on the patterns and rates of growth of species in relation to the post-mortem interval is required. ${ }^{23}$ Therefore, robust fungal analysis, dependent particularly on well-established microbial ecology techniques rather than conventional taxonomic methods alone, would enhance the evident and potential value of forensic mycology. Anderson and Cairney present an opportune and succinct review of the molecular techniques used to study fungal diversity and ecology in soils with total/direct $18 \mathrm{~S}$ rRNA gene or $18 \mathrm{~S}$ - $23 \mathrm{~S}$ rRNA gene internal transcribed spacer (ITS) as the principal targets. ${ }^{24}$ Furthermore, Damon et al. investigated an alternative fungal molecular marker, the mitochondrial cytochrome $c$ oxidase 1 (COX1) encoding gene, for environmental RNA-based analyses of metabolically active Agaricomycetes and Pezizomycotina communities. ${ }^{25}$ Although the discourse by 
Anderson and Cairney and Damon et al. was not intended for the forensic ecogenomic context, we propose that the strengths, limitations and novel approaches highlighted by these researchers are also transferable to, and must be explored for, the advancement and validation of forensic mycology. ${ }^{26}$

Generally, the reports, exemplified above, acknowledge the potential applicability and relevance of the methodologies that are currently adopted in soil-based forensic investigations. They also emphasise the need for additional, robust and sensitive microbial assessments of soils around burial environments and human decomposition to explore local dynamics and functions in more detail and, thus, extend taphonomic research. Also, identification of (core) microbial taxa linked to decomposition 'history' would, potentially, provide stronger or more accurate determinations of $\mathrm{PMI}^{27}$ Previous studies have already established that highthroughput sequencing techniques could play a key role in rapidly increasing the necessary comparative libraries. ${ }^{28}$ This comprehensive approach would directly address the observation by Tomberlin $e t$ al. of the need to streamline 'research in decomposition ecology, which promotes quantitative approaches to collecting and applying data to forensic investigations involving decomposing human remains ${ }^{2}{ }^{29}$

\section{Aquatic environments}

Despite the occurrence of human remains in bodies of water, little research has been conducted with a detailed analysis of taphonomic changes due to aquatic submersion..$^{30}$ Nevertheless, some studies have explored the potential roles of microbial communities in aquatic ecosystems for their effective and reliable application in human body crime scene investigations. For example, Kakizaki et al. used blood from twenty-two cadavers recovered from or near fresh or saline water and normal blood to model blood samples of victims found twenty-four hours after drowning. Culture-dependent and molecular homologous analyses of the 16S rRNA gene were used to determine the occurrence of marine bacteria in blood samples and, potentially, establish a protocol for victims of drowning. The researchers recorded distinct microbial profile differences of cadavers drowned in seawater compared with those drowned in fresh water (river, bathtub) and deposited on dry land. Specifically, homologous $16 \mathrm{~S}$ rRNA gene analysis of bioluminescent and/or blue colonies on $4 \%(\mathrm{w} / \mathrm{v}) \mathrm{NaCl}$-supplemented $\mathrm{TH}$ agar indicated a predominance of marine strains of the Photobacterium, Vibrio, Shewanella and Psychrobacter genera in blood of cadavers drowned in seawater. In contrast, non-marine strains, Aeromonas, Vagococcus, Staphylococcus and Pseudomonas spp were recovered from cadavers from a river, bathtub and dry land. ${ }^{31}$

Although more traditional diatom analyses can be cumbersome, ${ }^{32}$ a combination of bacterioplankton cultivation and marine or freshwater diatom counts was used by Kakizaki et al. to confirm drowning as the cause of death for a female body that had washed up on a beach after a typhoon. Despite extensive decomposition, the combined analysis of water samples from different organs (such as kidneys, liver and both lungs, including and excluding the pleura) provided conclusive evidence of drowning in fresh or brackish water with low salinity. ${ }^{33}$ 
In vitro studies have also been used to address knowledge gaps on the potential use of specific aquatic microbiological indicators for drowning and differentiation between incidences in waters of different salinities. ${ }^{34}$ These initiatives were complemented further by other research groups such as Dickson et al. who applied molecular-based PCR and sequencing of the 16S rRNA gene to determine links between microbial invasion, body decomposition in marine ecosystems and postmortem submersion interval (PMSI). Analysis of completely submerged pig (Sus scrofa L.) carcasses showed a sequential occurrence of specific microbial communities with distinctive diversities and compositions relative to specific PMSIs. Hence, although a predominance of Gammaproteobacteria was generally recorded, novel Bacteroidales genera showed distinct season- and submersion-specific colonisation patterns. Despite these, the authors highlighted deliberations by other workers that microbial composition trends, which then provide PMSI estimates, are dependent on several parameters including temperature, water depth, current, salinity, access to water surface (whether the body remains afloat or sinks), nature of the underlying substrate, water chemistry, presence of scavengers and clothing and trauma. Consequently, the post-mortem submersion interval determinations could probably be site-specific. ${ }^{35}$

These studies highlight that local aquatic environment analysis could be complemented by culture- and molecular-based studies of the microbial communities found in or on victims to provide a substantive link to the crime scene, even if the remains have been moved and/or decomposed. Further detailed, more robust and conclusive research (particularly regarding species distribution) is required, however, before the informed adoption of this approach in the crime investigative toolkit.

\section{Potential impacts of the human microbiome}

The human body is host to thousands of different bacterial species (see NIH HMP Working Group et al. and Wilson and Kong for comprehensive reviews) and the topmost layer of skin, the epidermis, has local characteristics that result in unique microecosystems. ${ }^{36}$ For example, the skin has a low $\mathrm{pH}$, low water activity and secretions from sudoriferous (sweat) and sebacious (oil) glands, with the epidermis contributing dead keratinised epithelial cells. Overall, the inherent properties of each organ lead to differences in bacterial community composition from one area of the body to another. These differences even occur in physiological proximity and/or depths, hence Grice et al. observed that hand bacterial profiles are different to those of the forearm. ${ }^{37}$

Furthermore, several symbiotic relationships exist between the human body and a wide range of bacteria, and common examples include the intestinal and skin microbiota. ${ }^{38}$ Also, personal lifestyles create distinct microenvironments that select for specific microbial communities or local microbial fingerprints that differ between individuals (Table 2). Thus Fierer et al. suggest that 'the collective genomes of our microbial symbionts may be more personally identifying than our own human genomes'. ${ }^{39}$ Since these interactions are constant but unique for 
each individual, they may afford valuable identification information for forensic investigations ante-mortem. A microbial community must, however, be relatively consistent over time and independent of transitory perturbations to constitute a unique 'microbial fingerprint'. ${ }^{40}$ This concept has been tested on different parts of the body including hands, elbows and forearms ${ }^{41}$ with the use of culture-based and 16S rRNA gene pyrosequencing analyses where the data recorded some core bacterial taxa together with distinct intra- and interpersonal bacterial associations. The distributions of different phylotypes were also dependent on other parameters including sex. Despite these findings, the occurrence of a microbial fingerprint for forensic applications remains the subject of considerable debate and experimental scrutiny. Its persistence post-mortem, particularly relative to different phases of decomposition, mandates comprehensive studies and is outside the scope of this article.

To date, several investigations of the application of microarrays to explore the human microbiome have been made and/or debated. For example, a review of community composition, dynamics and functional capacity of the human microbiota is presented by Paliy and Agans. The authors highlighted the application of metagenomics, metatranscriptomics, metaproteomics, metabolomics and metabonomics to understand the capacities of microbial communities to function and produce metabolites in response to specific interactions with the environment. Also, recent data comparing child gut microbiomes in response to long-term diets in industrialised (Europe, Amerindian) and emerging (Burkina Faso, Malawi) nations is explored..$^{42}$ Similarly, Bergström et al. reported on the gut low density array (GULDA), which they developed for rapid, quantitative, cost-effective and high throughput community dynamics analysis of typical and predominant core intestinal microbiome phyla including Firmicutes, Bacteroidetes, Actinobacteria, Proteobacteria and Verrucomicrobia. Despite the small sample size, the study data suggested a potential application of GULDA to assess the response of specific phylogenetic groups as a function of age, diet, functional food, antibiotics and health. ${ }^{43}$ Therefore, although experimental analyses are limited or not possible due to ethical guidelines, it seems likely that different human microbiome-based assays that have been used ante-mortem could be applied at real crime scenes to investigate their potential applicability to determine the health, lifestyle, socioeconomic and cultural background of an unidentified victim or suspect.

Although studies on human cadavers are lacking, animal model-based studies have suggested that spatio-temporal shifts in necrobiome community structure and composition can be used, potentially, for PMI estimates. ${ }^{44}$ Also, while comprehensive investigations are required, it seems plausible that person-specific microbiota would result in distinct post-mortem decomposition timelines. These would, in turn, lead to divergent effects on the dynamics of the surrounding environmental (burial) microbial communities. Thus post-mortem interval and time-since-burial calculations, as also based on forensic ecogenomic analyses, would be affected directly by the substrates and chemicals released by the decomposing body relative to several parameters such as its size, age, hygiene, diet and health (medication). 


\section{Future perspectives}

Apart from monitoring the effects of decomposition on microbial community dynamics, other potential applications of forensic ecogenomics may be considered. Some examples include: (i) use of species-specific and hierarchical oligonucleotide primer extension determinations ${ }^{45}$ to link environmental degradation to specific pollution sources ('environmental forensics') ${ }^{46}$ such as human or animal type faecal matter in surface water; (ii) analysis of samples of the oral microbiome (bite marks and buccal swabs), lip prints and skin microbiota (fingerprints and skin cells) using microarrays or genechips; and (iii) the examination of stable isotope profiles of decomposition products. ${ }^{47}$ Although presently theoretical, these innovative and high throughput tools have the potential to extend the forensic toolkit further. The typically rapid generation of large molecular and metabolomic data sets, coupled with robust and proven analysis and conventional intelligence gathering, could facilitate more comprehensive, efficient and expedient interpretation of the complete crime scene data set.

\section{Conclusions}

The introduction of DNA-based analysis revolutionised crime scene and forensic investigation protocols. As with any discipline, new challenges necessitate the development of novel approaches and/or the adoption of existing techniques from related fields. For different environmental biotechnologies, this process led to the increasing application of rapid, easy-to-use, high resolution, high throughput, robust and cutting-edge molecular microecophysiology techniques that typically result in data sets of high quantity and quality. Therefore, the aim of this article is to emphasise that the methods now common in exploring the molecular microbial ecology of soils, sediments and water have an exciting role to play in the future investigation of episodes of violence.

Although some key preliminary steps such as sample collection, storage and preparation, especially for representative and uncontaminated DNA/RNA/ protein/fatty acid recovery remain critical (and yet could be problematic in remote areas), the advantages and limitations of established and novel ecogenomic tools need to be considered specifically for application in forensic archaeological contexts. Hence, as exemplified in Table 1, rigorous testing and verification of some of these tools prior to their adoption, particularly in the microbioforensics of decomposition, is underway. 
Table 1: Current and potential applications of ecogenomic techniques in microbial forensics (adapted from Ralebitso-Senior et al.) ${ }^{48}$

Technique Current and potential applications/observations

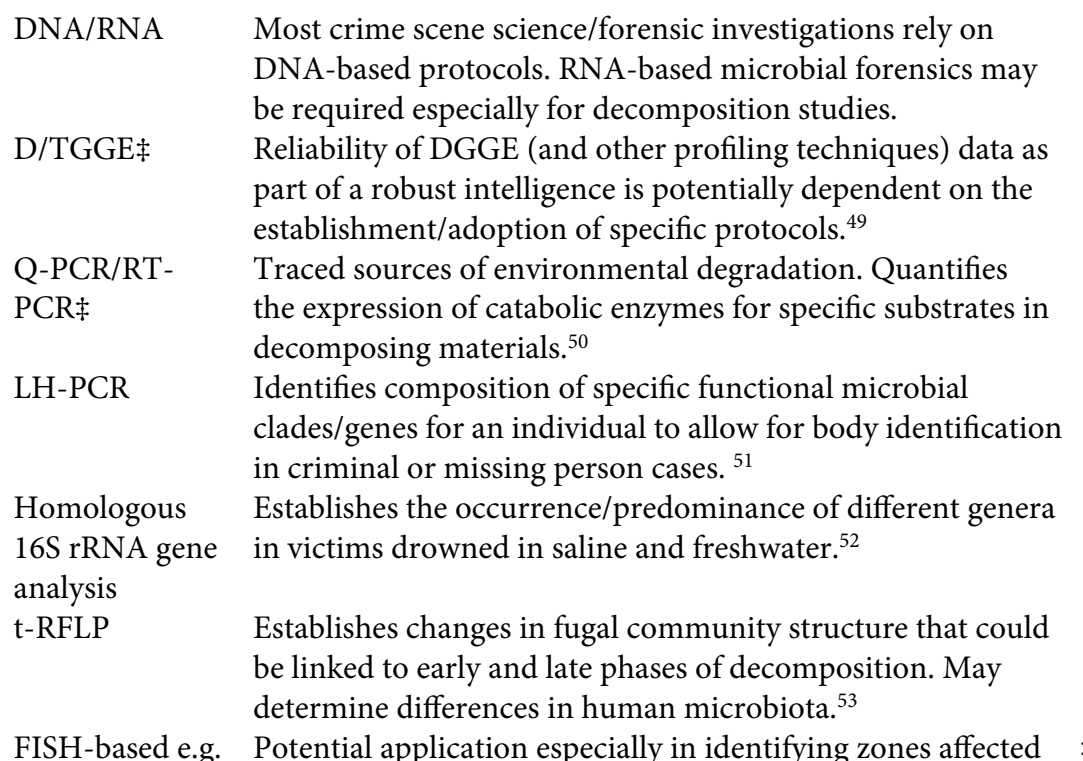

MAR-FISH, by decomposition. Estimation of the size and/or weight of

STAR-FISH the original buried material.

SIP

HOPE

GC/MS-based analysis for lipids (FAME). Combination with DNA-/RNA-/protein-/amino acid-based tracking of microbial communities/enzymes in response to decomposition $¥ .{ }^{54}$

Afford activity-specific comparisons between pristine and contaminated ecosystems (e.g. Bacteroidales-Prevotella distribution/predominance due to farming activities). Quantitative data may allow estimates of contaminant migration relative to source. ${ }^{55}$

Metagenomic Applicable: (i) pre-, during and post-decomposition; (ii) $\quad$ analysis above, within, below and away from decomposing material; and (iii) upstream, within and downstream of pollution point.

Microarrays $\quad$ Potential for bespoke platforms targeting common members $\ddagger$ of the human microbiota. Use existing arrays, e.g. GeoChip 2.0/3.0 and PhyloChip, in decomposition studies.

Clone libraries Highly applicable for defined microhabitats and human 'microbial fingerprinting'. ${ }^{56}$ 
Sequencing Identifies phylogenetic members/profiles indicative of and unique to decomposition history, defined 'microbial fingerprints' and tissue-specific human microbiotał. Provides data to design primers/probes, e.g. for microarrays. ${ }^{57}$

SDS-PAGE Applicable for rapid analysis of protein-based response to

FAME Lipid analysis of grave soil confirms disinterred grave location. Can be complemented with microbial community tracking to link profile dynamics as a result of decomposition. ${ }^{58}$

PLFA Robust evidence of microbial community structure changes in response to decomposition. ${ }^{59}$

CLPP Compares physiological/metabolic profiles between crime- $\quad$ and non-crime-scene samples.

$\$$ designates techniques that have not yet applied in microbial forensics; FISH: Fluorescent in situ hybridization; MAR-FISH: microautoradiography-fluoresence in situ hybridization; STAR-FISH: substrate-tracking autoradiography-FISH; SDS-PAGE: Sodium dodecyl sulphate polyacrylamide gel electrophoresis; CLPP: Community-level physiological profiling

Table 2: Influences on microbial communities on the person

\begin{tabular}{|c|c|}
\hline Lifestyle Variable & Details \\
\hline Hand sanitation & $\begin{array}{l}\text { Increased use of antibacterial hand gels and soaps reduces } \\
\text { bacterial adherence and colonisation. They also target specific } \\
\text { strains selecting the number and types of skin colonising } \\
\text { species. }^{60}\end{array}$ \\
\hline $\begin{array}{l}\text { Antibiotics / } \\
\text { medication }\end{array}$ & $\begin{array}{l}\text { These change the chemical composition of skin secretions } \\
\text { and, thus, the resident microbial strains. Specifically, } \\
\text { antibiotics are bactericidal to species around skin hair } \\
\text { follicles. }{ }^{61}\end{array}$ \\
\hline Smoking & $\begin{array}{l}\text { The habit has several effects on the skin including a decrease } \\
\text { in moisture making it more difficult for bacteria to find free } \\
\text { water in an already dry environment. }{ }^{62}\end{array}$ \\
\hline Age & $\begin{array}{l}\text { Bodily functions change with age potentially affecting } \\
\text { amounts/types of secretions hence the commensal microbial } \\
\text { profiles. Medical devices (catheters or prostheses) will affect } \\
\text { populations. }{ }^{63}\end{array}$ \\
\hline Sex & $\begin{array}{l}\text { Male and female bodies are characterised by different } \\
\text { communities, e.g. male skin generally supports higher } \\
\text { bacterial density while female skin has a lower density but } \\
\text { higher diversity. }{ }^{64}\end{array}$ \\
\hline
\end{tabular}


Body piercing Pierced areas are cleansed to reduce risk of infection, which affects the bacterial composition, while silver jewellery may influence bacterial composition due to antimicrobial properties. $^{65}$

Geographical Microorganisms are often acquired from the surrounding location environment and so it is possible to measure differences in species that are geographically region-specific. ${ }^{66}$

Occupation The palm, in particular, is in constant contact with other surfaces and/or areas of the body, e.g. manual labourers' hands are mostly subject to harsh treatment and extensive wear and tear depending on the materials handled, hence reducing colonisation by transient bacteria.

\section{Notes}

1 M. Cox, A. Flavel, I. Hanson, J. Laver and R. Wessling (eds), The Scientific Investigation of Mass Graves: Towards Protocols and Standard Operating Procedures (Cambridge, Cambridge University Press 2007).

2 A. Starkie, L. White and T. J. U. Thompson, 'An Investigation into the Effects of Decomposition on the Post-mortem Location of Trans-dermal Artefacts', Forensic Science International, 224 (2013), 68-72.

3 R. Bergmann, T. K. Ralebitso-Senior and T. J. U. Thompson, 'An RNA-based Analysis of Changes in Biodiversity Indices in Response to Sus Scrofa Domesticus Decomposition', Forensic Science International 241 (2014), 190-4; A. O. Olakanye, T. J. U. Thompson and T. K. Ralebitso-Senior, 'Changes to Soil Bacterial Profiles as a Result of Sus Scrofa Domesticus Decomposition', Forensic Science International 245 (2014), 101-6.

4 G. Fowler and T. J. U. Thompson, 'A Mere Technical Exercise? Challenges and Technological Solutions to the Identification of Individuals in Mass Grave Scenarios in the Modern Context', in É. Anstett and J.-M. Dreyfus (eds), Human Remains and Identification: Mass Violence Genocide and the 'Forensic Turn' (Manchester, University of Manchester Press, 2015), pp. 117-41.

5 S. M. Ali, S. Mahnaz and T. Mahmood, 'Rapid Genomic DNA Extraction (RGDE)', Forensic Science International: Genetic Supplement Series, 1:1 (2008), 63-5; M. Djuric, T. Varljen, A. Stanojevic and O. Stojkovic, 'DNA Typing from Handled Items', Forensic Science International: Genetic Supplement Series, 1:1 (2008), 411-12; P. Cormaci and A. Barbaro, 'DNA Typing from Lipstick Prints Left on the Skin', Forensic Science International: Genetic Supplement Series, 2:1 (2009), 125-6; W. Goodwin, A. Linacre and S. Hadi, An Introduction to Forensic Genetics (Oxford, Wiley-Blackwell, 2010).

6 A. Gunn, Essential Forensic Biology (London, Wiley-Blackwell, 2009); R. C. Janaway, S. L. Percival and A. S. Wilson, 'Decomposition of Human Remains', in S. L. Percival (ed.), Microbiology and Aging: Clinical Manifestations (New York, Humana Press, 2009), pp. 313-34; R. L. Gowland and T. J. U. Thompson, 
Human Identity and Identification (Cambridge, Cambridge University Press, 2013).

7 R. G. Breeze, B. Budowle and S. E. Schutzer (eds), Microbial Forensics (New York, Elsevier Academic Press, 2005), pp. 1-25; B. Budowle, R. Murch and R. Chakraborty, 'Microbial Forensics: The Next Forensic Challenge', International Journal of Legal Medicine, 119 (2005), 317-30; A. Ruffell and J. McKinley, 'Forensic Geoscience: Applications of Geology, Geomorphology and Geophysics to Criminal Investigations', Earth-Science Reviews, 69:3-4 (2005), 235-47; A. Ruffell, 'Forensic Pedology, Forensic Geology, Forensic Geoscience, Geoforensics and Soil Forensics', Forensic Science International, 202:1-3 (2010), 9-12; I. Petrisor, R. Parkinson, J. Horswell, J. Waters, L. Burgoyne, D. Catcheside, W. Dejonghe, N. Leys, K. Vanbroekhoven, P. Pattnaik and D. Graves, 'Microbial Forensics', in R. Morrison and B. Murphy (eds), Environmental Forensics: Contaminant Specific Guide (San Diego, Academic Press Elsevier, 2006), pp. 227-57.

8 M. S. Meyers and D. R. Foran, 'Spatial and Temporal Influences on Bacterial Profiling of Forensic Soil Samples', Journal of Forensic Science, 53:3 (2008), 652-60.

9 I. Douterelo, R. Goulder and M. Lillie, 'Soil Microbial Community Response to Land-Management and Depth, Related to the Degradation of Organic Matter in English Wetlands: Implications for the In Situ Preservation of Archaeological Remains', Applied Soil Ecology, 44:3 (2010), 219-27.

10 D. O. Carter, D. Yellowlees and M. Tibbett, 'Moisture can be the Dominant Environmental Parameter Governing Cadaver Decomposition in Soil', Forensic Science International, 200:1-3 (2010), 60-6.

11 W. Z. Rodriguez 3rd and W. M. Bass, 'Decomposition of Buried Bodies and Methods that May Aid in their Location', Journal of Forensic Sciences, 30:3 (1985), 836-52; L. A. Benninger, D. O. Carter and S. L. Forbes, 'The Biochemical Alteration of Soil Beneath a Decomposing Carcass', Forensic Science International, 180:2-3 (2008), 70-5; M. Tibbett and D. O. Carter, Soil Analysis in Forensic Taphonomy: Chemical and Biological Effects of Buried Human Remains (Boca Raton, CRC Press, 2008); K. L. Stokes, S. L. Forbes, L. A. Benninger, D. O. Carter and M. Tibbett, 'Decomposition Studies Using Animal Models in Contrasting Environments: Evidence from Temporal Changes in Soil Chemistry and Microbial Activity', in K. Ritz, L. Dawson and D. Miller (eds), Criminal and Environmental Soil Forensics (AK Houten, Springer, 2009), pp. 357-77; J. A. AitkenheadPeterson, C. G. Owings, M. B. Alexander, N. Larison and J. A. Bytheway, 'Mapping the Lateral Extent of Human Cadaver Decomposition with Soil Chemistry', Forensic Science International, 216:1-3 (2012), 127-34; A. R. Tumer, E. Karacaoglu, A. Namli, A. Keten, S. Farasat, R. Akcan, O. Sert and A. B. Odabaşi, 'Effects of Different Types of Soil on Decomposition: An Experimental Study', Legal Medicine, 15:3 (2013), 149-56.

12 J. Prangnell and G. McGowan, 'Soil Temperature Calculation for Burial Site Analysis', Forensic Science International, 191:1-3 (2009), 104-9.

13 D. W. Hopkins, P. E. J. Wiltshire and B. D. Turner, 'Microbial Characteristics 
of Soils from Graves: An Investigation at the Interface of Soil Microbiology and Forensic Science', Applied Soil Ecology, 14 (2000), 283-8.

14 T. C. F. Haslam and M. Tibbett, 'Soils of Contrasting pH Affect the Decomposition of Buried Mammalian (Ovis Aries) Skeletal Muscle Tissue', Journal of Forensic Sciences, 54:4 (2009), 900-4.

15 Carter et al., 'Moisture can be the Dominant', 60-6.

16 R. A. Parkinson, K.-R. Dias, J. Horswell, N. Greenwood, M. Tibbett and A. A. Vass, 'Microbial Community Analysis of Human Decomposition on Soil', in K. Ritz, L. Dawson and D. Miller (eds), Criminal and Environmental Soil Forensics (AK Houten, Springer, 2009), pp. 379-96.

17 L. I. Moreno, D. Mill, J. Fetscher, K. John-Williams, L. Meadows-Jantz and B. McCord, 'The Application of Amplicon Length Heterogeneity PCR (LH-PCR) for Monitoring the Dynamics of Soil Microbial Communities Associated with Cadaver Decomposition', Journal of Microbiological Methods, 84:3 (2011), 388-93.

18 M. Tibbett and D. O. Carter, 'Mushrooms and Taphonomy: The Fungi that Mark Woodland Graves', Mycologist, 17:1 (2003), 20-4; K. Ishii, M. Hitosugi, T. Yagichi and S. Tokudome, 'The Importance of Forensic Mycology', Legal Medicine, 9:5 (2007), 287; R. G. Menezes, A. Jain, T. Kanchan, F. N. P. Monteiro, S. Manipady and P. P. J. Rao, 'Forensic Mycology', Legal Medicine, 9:1 (2007), 48.

19 D. L. Hawksworth and P. E. Wiltshire, 'Forensic Mycology: The Use of fungi in Criminal Investigations', Forensic Science International, 206:1-3 (2011), 1-11.

20 D. O. Carter and M. Tibbett, 'Taphonomic Mycota: Fungi with Forensic Potential', Journal of Forensic Sciences, 48:1 (2003), 168-71; M. Hitosugi, K. Ishii, T. Yaguchi, Y. Chigusa, A. Kurosu, M. Kido, T. Nahai and S. Tokudome, 'Fungi can be a Useful Forensic Tool', Legal Medicine, 8:4 (2008), 240-2.

21 K. Ishii, M. Hitosugi, M. Kido, K. Nishimura, T. Hosoya and S. Tokudome, 'Analysis of Fungi Detected in Human Cadavers', Legal Medicine 8:3 (2006), 188-90.

22 R. E. M. Filho, J. J. C. Sidrim, R. A. Cordeiro, E. P. Caetano, M. F. G. Rocha and R. S. N. Brilhante, 'Trichophyton mentagrophytes Perforates Hair of Adult Corpses in the Gaseous Period', Journal of Forensic Sciences, 55:5 (2010), 1359-61.

23 R. G. Menezes, T. Kanchan, S. W. Lobo, A. Jain, N. B. Bhat and N. G. Rao, 'Cadaveric Fungi: Not Yet an Established Forensic Tool', Journal of Forensic Legal Medicine, 15:2 (2008), 124-6; P. P. J. Rao, G. P. Kumar, K. C. Trilok and S. Dhananjaya, 'A Response to "Cadaveric Fungi: Not Yet an Established Forensic Tool”', Journal of Forensic Legal Medicine, 15:8 (2008), 538-9; Hawksworth and Wiltshire, 'Forensic Mycology', 1-11.

24 A. Anderson and J. W. G. Cairney, 'Diversity and Ecology of Soil Fungal Communities: Increased Understanding through the Application of Molecular Techniques', Environmental Microbiology, 6:8 (2004), 769-79.

25 C. Damon, G. Barasso, C. Férandon, J. Ranger, L. Fraissinet-Tachet and R. Marmeisse, 'Performance of the COX1 Gene as a Marker for the Study of Metabolically Active Pezizomycotina and Agaricomycetes Fungal Communities from the Analysis of Soil RNA', FEMS Microbiology Ecology, 74:3 (2010), 693-705. 
26 Anderson and Cairney, 'Diversity and Ecology of Soil Fungal Communities', 769-79; Damon et al., 'Performance of the COX1 Gene', 693-705.

27 E. R. Hyde, D. P. Haarmann, A. M. Lynne, S. R. Buchell and J. F. Petrosino, 'The Living Dead: Bacterial Community Structure of a Cadaver at the Onset and End of the Bloat Stage of Decompostion', PLoS ONE, 8:10 (2013), 1-10; J. L. Metcalf, L. W. Parfrey, A. Gonzalez, C. L. Lauber, D. Knights, G. Ackermann, G. C. Humphrey, M. J. Gebert, W. V. Treuren, D. Berg-Lyons, K. Keepers, Y. Guo, J. Bullard, N. Fierer, D. O. Carter and R. Knight, 'A Microbial Clock Provides an Accurate Estimate of the Postmortem Interval in a Mouse Model System', eLIFE, 2:e01104 (2013); J. L. Pechal, T. L. Crippen, A. M. Tarone, A. J. Lewis, J. K. Tomberlin and M. E. Benbow, 'Microbial Community Functional Change During Vertebrate Carrion Decomposition', PLoS ONE, 8:11 (2013), 111.

28 G. T. Howard, D. Bronwyn and E. J. Watson-Horzelski, 'Characterization of the Soil Microbial Community Associated with the Decomposition of a Swine Carcass', International Biodeterioration and Biodegradation, 64 (2010), 300-4; V. Reeb, A. Kolel, T. R. McDermott and D. Bhattacharya, 'Good to the Bone: Microbial Community Thrives within Bone Cavities of a Bison Carcass at Yellowstone National Park', Environmental Microbiology, 13:9 (2011), 2403-15; J. L. Pechal, T. L. Crippen, M. E. Benbow, A. M. Tarone, S. Dowd and J. K. Tomberlin, 'The Potential Use of Bacterial Community Succession in Forensics as Described by High Throughput Metagenomic Sequencing', International Journal of Legal Medicine, 128:1 (2014), 193-205.

29 J. K. Tomberlin, M. E. Benbow, A. M. Tarone and R. M. Mohr, 'Basic Research in Evolution and Ecology Enhances Forensics', Trends in Ecology and Evolution, 26:2 (2011), 53-5.

30 C. E. L. Thompson, S. Ball, T. J. U. Thompson and R. L. Gowland, 'The Abrasion of Modern and Archaeological Bones by Mobile Sediments: The Importance of Transport Modes', Journal of Archaeological Science, 38:4 (2011), 784-93; R. DeBattista, T. J. U. Thompson, C. E. L. Thompson and R. L. Gowland, 'A Comparison of Surface Features on Submerged and Non-submerged Bone Using Scanning Electron Microscopy', Journal of Forensic and Legal Medicine, 20:6 (2013), 770-6.

31 E. Kakizaki, K. Takahama, Y. Seo, S. Kozawa, M. Sakai and N. Yukawa, 'Marine Bacteria Comprise a Possible Indicator of Drowning in Seawater', Forensic Science International, 176:2-3 (2008), 236-47.

$32 \mathrm{Ibid} ; \mathrm{G}$. T. Swindles and A. Ruffell, 'A Preliminary Investigation into the Use of Testate Amoebae for the Discrimination of Forensic Soil Samples', Science and Justice, 49:3 (2009), 182-90.

33 E. Kakizaki, S. Kozawa, H. Matsuda, E. Muraoka, T. Uchiyama, M. Sakai and N. Yukawa, 'Freshwater Bacterioplankton Cultured from Liver, Kidney and Lungs of a Decomposed Cadaver Retrieved from a Sandy Seashore: Possibility of Drowning in a River and then Floating Out to Sea', Legal Medicine 12:4 (2010), 195-9.

34 E. Kakizaki, S. Kozawa, N. Imamura, T. Uchiyama, S. Nishida, M. Sakai and N. Yukawa, 'Detection of Marine and Freshwater Bacterioplankton in Immersed Victims: Postmortem Bacterial Invasion Does Not Readily Occur', Forensic 
Science International, 211:1-3 (2011), 9-18; E. Kakizaki, S. Kozawa, H. Matsuda, E. Muraoka, T. Uchiyama, M. Sakai and N. Yukawa, 'In Vitro Study of Possible Microbial Indicators for Drowning: Salinity and Types of Bacterioplankton Proliferating in Blood', Forensic Science International, 204:1-3 (2011), 80-7.

35 G. C. Dickson, R. T. Poulter, E. W. Mass, P. K. Probert and J. A. Keiser, 'Marine Bacterial Succession as a Potential Indicator of Postmortem Submersion Interval', Forensic Science International, 209:1-3 (2011), 1-10.

36 NIH HMP Working Group, J. Peterson, S. Garges, M. Giovanni, P. McInnes, L. Wang, J. A. Schloss, V. Bonazzi, J. E. McEwen, K. A. Wetterstrand, C. Deal et al., 'The NIH Human Microbiome Project', Genome Research, 19 (2009), 2317-23; M. Wilson, Bacteriology of Humans: An Ecological Perspective (Victoria, WileyBlackwell, 2009); H. H. Kong, 'Skin Microbiome: Genomics-based Insights into the Diversity and Role of Skin Microbes', Trends in Molecular Medicine, 17:6 (2011), 320-8.

37 E. A. Grice, H. H. Kong, G. Renaud, A. C. Young, G. G. Bouffard, R. W. Blakesley, T. G. Wolfsberg, M. L. Turner and J. A. Segre, 'A Diversity Profile of the Human Skin Microbiota', Genome Research, 18:7 (2008), 1043-50; E. A. Grice, H. H. Kong, S. Conlan, C. B. Deming, J. Davis, A. C. Young, NISC Comparative Sequencing Program, G. G. Bouffard, R. W. Blakesley, P. R. Murray, E. D. Green, M. L. Turner and J. A. Seger, 'Topographical and Temporal Diversity of the Human Skin Microbiome', Science, 324:5931 (2009), 1190-2.

38 E. G. Zoetendal, M. Rajilić-Stojanović and W. M. de Vos, 'High-throughput Diversity and Functionality Analysis of the Gastrointestinal Tract Microbiota', Gut, 57:11 (2008), 1605-15; Grice et al., 'Topographical and Temporal Diversity', 1190-2; M. Li, H. Zhou, W. Hua, B. Wang, S. Wang, G. Zhao, L. Li, L. Zhao and X. Pang, 'Molecular Diversity of Bacteroides spp. in Human Fecal Microbiota as Determined by Group-specific 16S rRNA Gene Clone Library Analysis', Systematic and Applied Microbiology, 32:3 (2009), 193-200; Kong, 'Skin Microbiome', 320-8; N. Ottman, H. Smidt, W. M. de Vos and C. Belzer, 'The Function of Our Microbiota: Who Is Out There and What Do They Do?', Frontiers in Cellular and Infection Microbiology, 2:104 (2012), 1-11.

39 N. Fierer, C. Lauber, N. Zhou, D. McDonald, E. Costello and R. Knight, 'Forensic Identification Using Skin Bacterial Communities', Proceedings of the National Academy of Sciences USA, 107:14 (2010), 6477-81.

40 Ibid.

41 N. Fierer, M. Hamady, C. L. Lauber and R. Knight, 'The Influence of Sex, Handedness and Washing on the Diversity of Hand Surface Bacteria', Proceedings of the National Academy of Sciences USA, 105:46 (2008), 17994-9; Grice et al., 'Topographical and Temporal Diversity', 1190-2.

42 O. Paliy and R. Agans, 'Application of Phylogenetic Microarrays to Interrogation of Human Microbiota', FEMS Microbiology Ecology, 79:1 (2012), 2-11.

43 A. Bergström, T. R. Licht, A. Wilcks, J. B. Andersen, L. R. Schmidt, H. A. Grønlund, L. K. Vigsnaes, K. F. Michaelsen and M. I. Bahl, 'Introducing Gut Low-density Array (GULDA) - A Validated Approach for qPCR-based Intestinal Microbial Community Analysis', FEMS Microbiology Letters, 337:1 (2012), 38-47. 
44 Hyde et al., 'The Living Dead', 1-10; Metcalf et al., 'A Microbial Clock', e01104; Pechal et al., 'Microbial Community Functional Change', 1-11; Pechal et al., 'The Potential Use of Bacterial Community Succession', 193-205.

45 R. Lamendella, J. W. Santo Domingo, A. C. Yannarell, S. Ghosh, G. Di Giovanni, R. Mackie and D. B. Oerther, 'Evaluation of Swine-specific PCR Assays Used for Fecal Source Tracking and Analysis of Molecular Diversity of Swine-specific “Bacteroidales" Populations', Applied and Environmental Microbiology, 75:18 (2009), 5787-96; P. Y. Hong, J. H. Wu and W. T. Liu, 'A High-throughput and Quantitative Hierarchical Oligonucleotide Primer Extension (HOPE)based Approach to Identify Sources of Faecal Contamination in Water Bodies', Environmental Microbiology, 11:7 (2009), 1672-81.

46 Petrisor et al., 'Microbial Forensics', 227-57; Ruffell, 'Forensic Pedology', 9-12.

47 J. D. Neufeld, M. Wagner and J. C. Murrell, 'Who Eats What, Where and When? Isotope-labelling Experiments are Coming of Age', The ISME Journal, 1 (2007), 103-10; D. Bull, R. Berstan, A. Vass and R. P. Evershed, 'Identification of a Disinterred Grave by Molecular and Stable Isotope Analysis', Science and Justice, 49:2 (2009), 142-9.

48 T. K. Ralebitso-Senior, E. Senior, R. Di Felice and K. Jarvis, 'Waste Gas Biofiltration: Advances and Limitations of Current Approaches in Microbiology', Environmental Science Technology, 46:16 (2012), 8542-73.

49 A. Lerner, Y. Shor, A. Vinokurov, Y. Okon and E. Jurkevitch, 'Can Denaturing Gradient Gel Electrophoresis (DGGE) Analysis of Amplified 16S rDNA of Soil Bacterial Populations be Used in Forensic Investigations?', Soil Biology and Biochemistry, 38 (2006), 1188-92.

50 Lamendella et al., 'Evaluation of Swine-specific PCR Assays', 5787-96; Howard et al., 'Characterization of the Soil Microbial Community', 300-4.

51 Moreno et al., 'The Application of Amplicon Length Heterogeneity PCR (LHPCR)', 388-93.

52 Kakizaki et al., 'Marine Bacteria', 236-47.

53 Parkinson et al., 'Microbial Community Analysis', 379-96; A. Camarinha-Silva, M. L. Wos-Oxley, R. Jáuregui, K. Becker and D. H. Pieper, 'Validating T-RFLP as a Sensitive and High-throughput Approach to Assess Bacterial Diversity Patterns in Human Anterior Nares', FEMS Microbiology Ecology, 79:1 (2011), 98-108.

54 Bull et al., 'Identification of a Disinterred Grave', 142-9.

55 Hong, Wu and Liu, 'A High-throughput and Quantitative Hierarchical Oligonucleotide Primer Extension', 1672-81; Lamendella et al., 'Evaluation of Swine-specific PCR Assays', 5787-96.

56 Reeb et al., 'Good to the Bone', 2403-15.

57 Zoetendal et al., 'High-throughput Diversity', 1605-15; Howard et al., 'Characterization of the Soil Microbial Community', 300-4; Kong, 'Skin Microbiome', 320-8; Pechal et al., 'Microbial Community Functional Change', 1-11; Pechal et al., 'The Potential Use of Bacterial Community Succession', 193-205.

58 Bull et al., 'Identification of a Disinterred Grave', 142-9.

59 Parkinson et al., 'Microbial Community Analysis', 379-96. 
60 W. R. Jarvis, 'Handwashing - the Semmelweis lesson forgotten?', Lancet, 344:8933 (1994), 1311-12.

61 S. Purdy and D. de Berker, 'Clinical Review: Acne', British Medical Journal, 333 (2006), 949-53.

62 A. Freiman, G. Bird, A. Metelitsa, B. Barankin and G. Lauzon, 'Cutaneous Effects of Smoking', Journal of Cutaneous Medicine and Surgery, 8 (2004), 415-23.

63 Wilson, Bacteriology of Humans: An Ecological Perspective.

64 Camarinha-Silva et al., 'Validating T-RFLP', 98-108.

65 M. Rai, A. Yadav and A. Gade, 'Silver Nanoparticles as a New Generation of Antimicrobials', Biotechnology Advances, 27:1 (2009), 76-83; Starkie, White and Thompson, 'An Investigation into the Effects of Decomposition', 68-72.

66 H. Ikegaya, H. Motani, P. Saukko, K. Sato, T. Akutsu and K. Sakurada, 'BK Virus Genotype Distribution Offers Information of Tracing the Geographical Origins of Unidentified Cadaver', Forensic Science International, 173:1 (2007), 41-6; Paliy and Agans, 'Application of Phylogenetic Microarrays', 2-11. 